\title{
MARQUINE, ELISANGELA
}

Mestranda, Universidade São Judas Tadeu, elimarquine@metastands.com.br

\section{MACEDO, ADILSON COSTA}

Doutor, Universidade São Judas Tadeu,ac.macedo@terra.com.br

\begin{abstract}
RESUMO
Este é um estudo sobre a arquitetura dos estandes imobiliários construídos no mesmo lugar onde o empreendimento imobiliário que representa será implantado. Da análise de um significativo número de projetos no Estado de São Paulo resultou um elenco de tipos e sua classificação conforme a finalidade comercial. A investigação, centrada na experiência brasileira, tomou como referência exemplos de outros países, particularmente quanto aos aspectos programáticos de apoio à seleção do que se considerou como tipo. Como espaço edificado o estande imobiliário tem sua origem associada aos primeiros pontos de venda de imóveis na cidade de São Paulo, Brasil, local da pesquisa. Neste contexto, onde a diversificação dos bairros é acentuada, torna-se evidente uma clara influência de aspectos socioeconômicos e culturais que afetam os estandes de vendas. Espera-se que a pesquisa tanto possa contribuir para o estudo, a concepção e o projeto de estandes de venda, entendidos como edifícios temporários, quanto também ser útil para aqueles que trabalham no marketing imobiliário.
\end{abstract}

PALAVRAS-CHAVE: estande imobiliário; arquitetura temporária; mercado imobiliário.

\section{ABSTRACT}

This is a study on the architecture of the stands built in the same place where the real estate development that it represents will be deployed. The analysis of a significant number of projects resulted in a list of patterns and classification according to their commercial purpose. The research focused on the Brazilian experience, but took examples from other countries, particularly in the programmatic aspects related to the selection of patterns. As a type of building, the current sales booth has its origin linked to the first real estate sales points in São Paulo, Brazil: the research site. In this context of sharped diversification of neighborhoods, there is a clear influence of socioeconomic and cultural aspects in real estate affecting the sales booths. We hoped that the research can contribute to the planning and design of sales stands, as temporary buildings, and be useful for those working in the real estate marketing.

KEY-WORDS: real estate booth, temporary architecture, real estate market.

\section{INTRODUÇÃO}

O estande imobiliário é uma edificação temporária que tem sua existência dependente do período de comercialização do empreendimento. Trata-se, portanto, de uma construção com ciclo de vida curto, sendo todas as medidas e estratégias relacionadas a sua concepção, projeto, execução e operação idealizadas com o objetivo de favorecer a venda do empreendimento que representa. Quando não há espaço no terreno, começada a obra o estande é eliminado mesmo que as vendas não se concluam, a favor de um local com área reduzida ainda no terreno e, posteriormente, passando a ocupar parte de um dos pavimentos do prédio em construção, ocasião em que passa a ser um simulacro do escritório da imobiliária.

No conjunto do empreendimento o estande é considerado um componente temporário, sendo por um lado espaço utilitário, e por outro expositivo, cujo objetivo é atrair a atenção do cliente, servindo como ferramenta de venda. Seu projeto depende de um bom programa de necessidades, no qual a questão funcional é simples, devendo haver especial atenção para como será disposto o projeto a ser comercializado, e geralmente usando painéis com desenhos, fotos, maquete ou vídeo. Assim, os requisitos do marketing tornam-se parte do programa, relacionando a visão daquilo que deverá vir a ser com as características do público comprador.

Como tema em estudo, o estande de vendas sugere apreciações com vários enfoques, incluindo abordagens como: a questão do marketing como matéria próxima à sua concepção; a construção em si do objeto; as tendências de arquitetura aplicada ao projeto; o ideário teórico associado a evolução histórica dos pavilhões de exposição e conceitos recentes de arquitetura efêmera. Tendo consciência de todas essas possibilidades, neste artigo optou- 
se pela análise e classificação de tipos como arquitetura e construção, relacionadas às dimensões do empreendimento, à disponibilidade de terreno para sua construção, aos critérios de organização do programa de necessidades (incluindo os itens do marketing) e ao projeto de arquitetura em si.

Para tanto foram considerados os estandes para lançamentos residenciais, comerciais ou mistos, de acordo com a situação de implantação no terreno e com a estratégia comercial da incorporadora. Em seguida, para validação e registro dos tipos foi realizado um levantamento de projetos destes estandes no Estado de São Paulo. Como material de pesquisa foi utilizado o acervo disponível nos portfólios online de arquitetos, decoradores e construtores especializados em estandes. Com o uso do Google Street View, verificou-se os lançamentos das maiores incorporadoras a fim de capturar imagens dos estandes existentes ou recentemente demolidos. Esse levantamento resultou em um acervo composto por aproximadamente cento e cinquenta exemplares, número julgado significativo para a caracterização pretendida. Como resultado espera-se obter uma classificação de tipos e exemplos, que deverá tornarse parte de um manual nesse campo.

\section{BREVE HISTÓRICO DOS ESTANDES IMOBILIÁRIOS}

A investigação do marketing imobiliário no decorrer do século XX, constatado por meio do levantamento de matérias e anúncios em jornais e revistas, mostra que os estandes imobiliários surgiram na cidade de São Paulo na década de cinquenta. São marcos de referência o lançamento de dois grandes empreendimentos: o Edifício COPAN e o Conjunto Nacional. Esses primeiros exemplares - cuja nomenclatura "estande" na época ainda não havia sido definida -, nada mais eram do que uma versão reduzida do escritório da imobiliária ou sede da incorporadora locados temporariamente no terreno, sem nenhum detalhe arquitetônico marcante; sendo desses o formato que influenciou a configuração dos estandes como são conhecidos: as vitrines na fachada e um espaço de atendimento marcado pela presença de várias mesas de corretores. Fotos da Companhia City (City of São Paulo improvements and freehold land company), e da Imobiliária Domingos Leardi, situadas no Centro da cidade, ilustram o aspecto dessas instalações da época (Figura 1).

Antes desse período, quando o principal produto imobiliário era o loteamento, o atendimento ao público no mercado imobiliário dividia-se entre os plantões de final de semana que ocorriam regularmente nos loteamentos, e os escritórios das imobiliárias e construtoras. Nos plantões eramusadastendas, guardasóis e outras coberturas improvisadas com finalidade de abrigo, sendo restritas a casos muito específicos a construção de edificações no local. São exemplos deste período o loteamento Jardim Europa, em 1922, onde foi construído um escritório, e os loteamentos Alto da Lapa e Pacaembu, em 1922 e 1930 respectivamente, onde foram construídas casas decoradas.

A partir da década de cinquenta, motivados pelo mercado emergente, os construtores e investidores verificaram que manter um ponto de atendimento no local permitia maior eficiência no fechamento de vendas evisitas espontâneas, levando os interessados diretamente ao lugar do lançamento, de modo que o cliente podia ser atendido e ter toda a transação, ou parte dela, realizada no terreno da obra. A gradativa ampliação do mercado passou a exigir maiores esforços para a demonstração do produto.

Figura 1 - Vitrine da Cia City na década de 20 e interior da Imobiliária Domingos Leardi na década de 40.
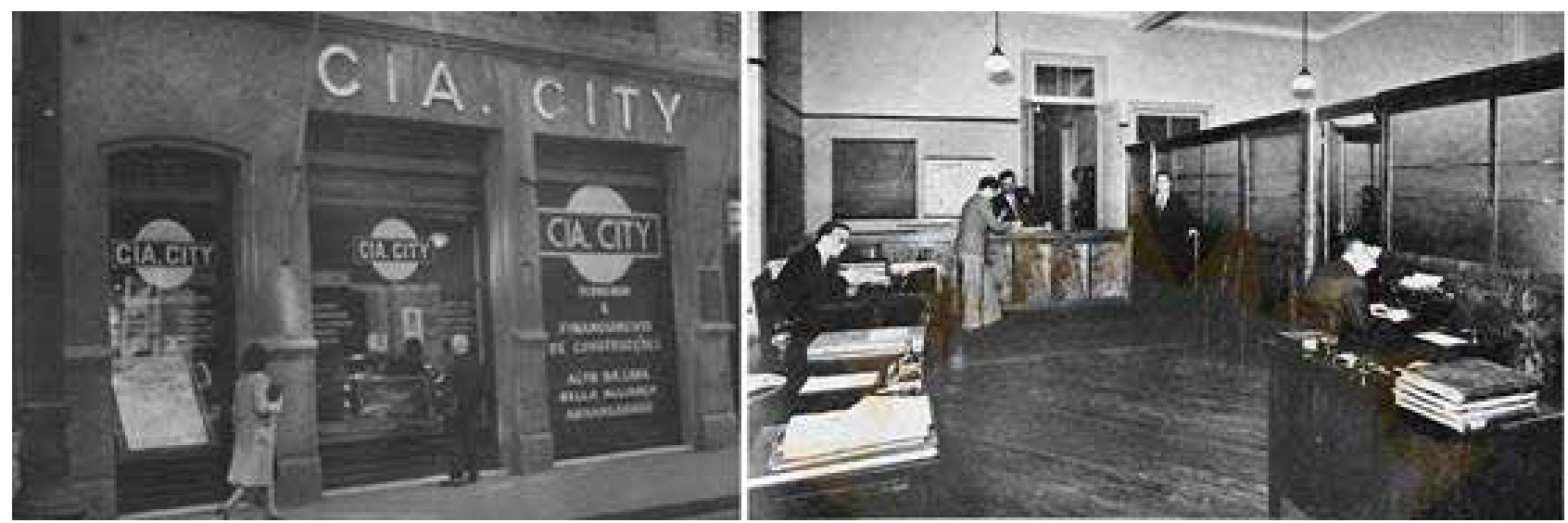

Fonte: <https://quandoacidade.wordpress.com/2014/12/17/a-cidade-era-mais-gentile/cia-city-rualibero-badaro/> acesso em 10/08/2016 e Revista Acrópole № 22. Fevereiro de 1940. 
O modelo de negócio da incorporação imobiliária exerceu considerável influência na instalação do ponto de venda no terreno, uma vez que os pagamentos começam a acontecer antes da materialização da propriedade. Surgiu daí a necessidade da presença do estande no terreno, transmitindo sensação de segurança para o comprador. A adoção deste procedimento de venda foi reforçada pela participação de bancos para financiamento e por questões legais. Outra possível influência indireta na consolidação dos estandes foi o preconceito que existia contra moradias verticais em condomínio na primeira metade do Século XX (DA SILVA, 2007; PINHEIRO, 2008), tempo em que foram construídos grandes edifícios com pequenas unidades residenciais no centro da Cidade de São Paulo e arredores.

Outro fato a ser registrado com relação ao surgimento e consolidação dos estandes foi a chegada de agências de publicidade americanas ao Brasil nos anos 1950, reforçando a necessidade da experiência do cliente in loco. Os americanos já possuíam know-how com a comercialização de empreendimentos e com iniciativas específicas de promoção e configuração do ponto de venda para o mercado imobiliário. Em 1958, havia um completo dossiê de apoio para a montagem do ponto de venda de lançamentos imobiliários nos EUA, incluindo reflexão e propostas que iam desde como deixar atraentes as fachadas das casas-modelo, até a melhor forma de dispor cartazes, maquetes e informações nos escritórios de vendas e a realização de eventos para atrair o público.

Na década de 1960 surgiram nos anúncios as primeiras aparições do nome "estande", porém, não se percebe nenhuma alteração com relação ao conceito do ponto de venda no local do lançamento. Relatos da época indicam que até barracões de madeira eram utilizados como instalação temporária (BASTOS, 2004; VILARINO, 2000 apud MORAES, 2013).

Avançando para 1970, e para uma São Paulo maior, mais populosa e familiarizada com a verticalização, surgiu O Banco Nacional de Habitação (BNH), favorecendo o crédito imobiliário. Anova contingencia induziu uma onda de lançamentos por toda a cidade. Havia demanda e crédito e, nesse momento, os incorporadores bateram recordes de faturamento ao mesmo tempo em que enfrentaram um cenário de grande concorrência, situação que trouxe maior cautela quanto à campanha e ao ponto de vendas.

Em 1973, a pauta do marketing imobiliário ganhou peso estratégico, focado na rápida comercialização dos empreendimentos. A Construtora Gomes de Almeida
Fernandes passou a inserir mecanismos de marketing em todos os níveis do negócio, realizando um curso nos setores de administração, vendas e publicidade. Em 1974, a Construtora Alfredo Mathias, construiu um estande de $600 \mathrm{~m}^{2}$ para o lançamento do condomínio Portal do Morumbi, considerada a maior e mais cara campanha desse tipo na época. Ainda na década, surgiram os primeiros estudiosos do marketing imobiliário, como Psillakis, em 1975, que pesquisou o comportamento do consumidor diante do produto imobiliário. Sobre o período, um grande incorporador relatou que o ritmo vertiginoso das vendas liquidava o empreendimento antes da finalização da construção do estande, sendo utilizado então um iglu inflável (ABUSSAMRA, 2007, p. 57).

Em meados da década de 1980 até 1990, os estandes já semelhantes aos atuais se consolidaram, num momento em que eclodiram os lançamentos de empreendimentos de alto e médio padrão. Surgiram, então, as empresas especializadas na construção de estandes, formadas por técnicos oriundos das construtoras responsáveis pelos edifícios, consolidando-se um nicho específico de interesse dentro da construção civil. Passouse a experimentar a utilização de estruturas metálicas leves e o fechamento por painéis de gesso acartonado, pelo sistema drywall, técnica construtiva que, por apresentar maior concordância com o aspecto temporário dessas edificações, se consolidou e é empregada até hoje.

Em fins do século $X X$, o espaço de atendimento mudou de dimensão, tanto pela tentativa de impressionar o público com o tamanho do estande, como para abrigar as novas mídias de representação do empreendimento, elaboradas por meio dos novos recursos de computação e da maior ousadia na comunicação visual, que começou a acontecer partir de 1995 e que é notada nos primeiros anos do século XXI. O uso do vidro também pode ser pontuado como item influente na arquitetura do estande, pois a partir da década de 1990 seu uso como elemento de fachada cresceu drasticamente no Brasil. Esses recursos permitiam a elaboração de plantas humanizadas, coloridas e computadorizadas, vistas de áreas comuns decoradas, e uma forma mais ilustrada e realista de representar o edifício pronto, inserido no entorno. Além dessas possibilidades, fotos dos apartamentos decorados começaram a ser usadas nos anúncios, agora impreterivelmente reproduzidos em cores. A arte e a representação na propaganda não eram mais atividades artísticas feitas à mão. Visualmente com relação ao empreendimento, passou a haver mais material para exibir, o que interferiu diretamente na configuração e uso desses espaços de exibição. 
Nos primeiros anos do século XXI, aprimoraramse as técnicas e os conceitos de segmentação de público, em conjunto com o marketing e a publicidade. O apelo à qualidade de vida aparece de maneira expressiva neste momento. Sensibilidade no posicionamento do produto passa a ser um fator determinante de comunicação com o público: além da concorrência dentro do próprio mercado imobiliário, o consumidor passa a ser cada vez mais exigente e visual. Tal exigência se reflete na configuração espacial do estande, onde em grande parte dos lançamentos são identificadas características do empreendimento como componentes de visual merchandising. São exemplos dessa representação as Figuras 2A e 2B.

Figura 2 - Contraste do moderno com o neoclássico em estandes recentes, dois estilos muito usados pelo mercado
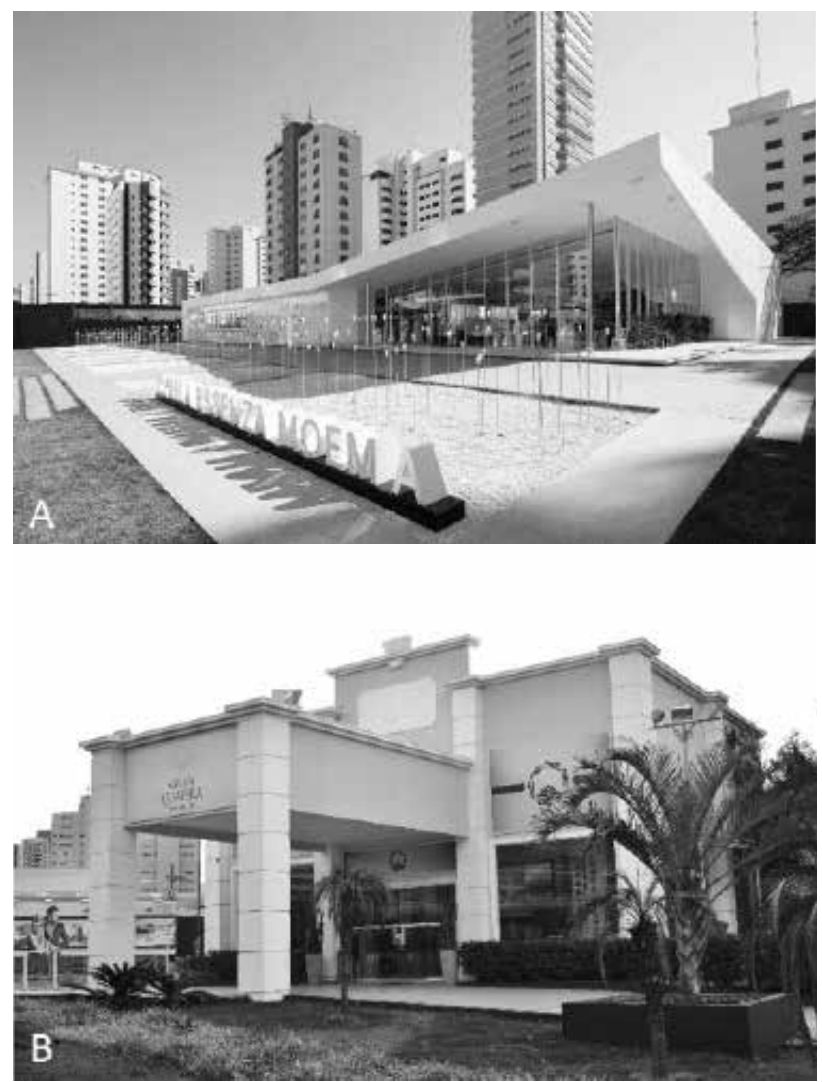

Fonte: Figura 2A JA Arquitetos; Figura 2B Foto dos autores.

Não apenas o visual merchandising é notado desde fins do século XX, mas o movimento do mercado que permite novos canais de comunicação com o cliente através de meios digitais, virtuais e locais. Há uma mudança no comportamento do consumidor no sentido de que ao mesmo tempo em que várias ferramentas e métodos promocionais despontam, fica cada vez mais difícil vender, pois o consumidor desenvolveu um rigoroso filtro para lidar com as constantes e invasivas mensagens publicitárias que o cercam o tempo inteiro. Atualmente, se fala na revolução do ponto de venda. Não apenas o anúncio é lançado ao público, mas o próprio espaço físico vai aonde quer que ele esteja. Não haveria como o mercado imobiliário abster-se de tal movimento.

\section{OS TIPOS DE ESTANDES}

Sob a perspectiva de estudo dos tipos, a história mostra que, no decorrer do século XX o estande imobiliário foi constantemente adaptado às novas demandas condicionadas pelo mercado, pelos recursos construtivos e pelo comportamento do público. Porém, enquanto o formato do estande como é visto hoje se desenvolvia, a modalidade de diferentes instalações provisórias de materiais diversos permaneceu usual. Atualmente, destas restou somente a tenda, porém nas áreas urbanas ela é apenas provisória, enquanto o estande não é finalizado. A variedade de tipos encontrada atualmente nada mais é do que a sofisticação de todas as tentativas empregadas anteriormente, agora submetidas a novas técnicas construtivas, recursos estéticos e a abertura de campo para exposição.

As casas decoradas da década de 20 e 30, os escritórios centrais das imobiliárias, os escritórios no local, as tendas e guarda-sóis, os iglus infláveis, barracões de madeira e os estandes atuais, identificados no histórico, denotam os esforços do mercado imobiliário em adaptar-se a peculiar situação do ciclo de venda de seu produto num momento onde, fora das sedes dos incorporadores e imobiliárias, apenas o próprio terreno do lançamento era enxergado como um "ponto de venda" possível. Os diversos tipos de edificações e instalações, temporários ou não, vem depois de sua designação como local propício para essa atividade.

Atualmente, existem recursos disponíveis para que os limites do entorno imediato do lançamento imobiliário sejam rompidos. Tal medida corresponde a necessidade de estabelecer a maior presença possível perante o consumidor, posicionandose aonde possa haver interesse pelo produto e disputando mercado com a concorrência. Hoje o estande pode estar em qualquer lugar e por consequência, assumir diferentes formas.

A configuração mais comum do projeto de estandes é caracterizada por uma edificação nova localizada no terreno onde vai ser implantado o novo empreendimento, porém não é a única. Essa flexibilização representa um ganho maior para o marketing imobiliário do que o encantamento 
proporcionado pelas ferramentas tecnológicas através das quais o empreendimento pode ser visualizado, pois antes de que se chegue a questão da experiência do consumidor no ponto de venda, é importante que o anunciante e o produto sejam vistos.

Um fato interessante com relação aos tipos observados é que, com exceção dos estandes móveis e dos locados em pátios descobertos, de abordagem mais popular, não existe restrição em função do empreendimento: a escolha está ligada a estratégia e verba disponível para o lançamento.

Estudadas as estratégias de projeto empregadas por empreendedores diferentes com relação ao critério de implantação, que é o que realmente condiciona o aspecto da edificação e das instalações, foram identificados os seguintes tipos de estandes:

\section{Tipo 1 - Localizado em ponto selecionado para dar ideia do terreno como um todo}

Sua origem vem da época do primeiro boom imobiliário - anos cinquenta e sessenta do século passado - quando passou-se a construir pequenos escritórios para sediar as atividades de venda do empreendimento no próprio terreno, em substituição as tendas e barracões improvisados de madeira. É a primeira construção feita no terreno do lançamento, destacando-se nos estandes atuais:

- Implantação recuada da rua, longe das divisas do terreno, procurando não prejudicar a vista do lote como um todo.

- Espaços generosos para vagas de automóveis.

- Lote, tratado parcialmente ou por inteiro com paisagismo.

- Pavimentação com material fácil para remover nos locais de circulação.

- Configuração espacial formada pelo salão de atendimento e disposição do material do empreendimento, e do anexo de apoio com copa, depósito, sala dos corretores, WCS e demais dependências pertinentes.

Este tipo de estande, em função do sistema construtivo e do tamanho que pode ter, é o que permite maior requinte na apresentação do empreendimento, pois permite que sejam criadas cenografias e ambientes diversos que valorizem o trajeto de exibição, bastante solicitado pelos corretores; além da presença do apartamento decorado, que pode estar dentro do estande, junto a ele numa só volumetria, ou separado e ligado por passarela. São construídos de forma modesta, ou podem se apresentar de maneira mais sofisticada, incorporando características do empreendimento ou de sua identidade. Como toda edificação, precisa seguir as diretrizes legais municipais, tendo como única específica o decreto 55.036 de 15 de abril de 2014, que limita sua altura a 6 metros uma vez encostados nas divisas do terreno.

Sua estrutura é feita com perfis metálicos leves, sobre fundação superficial, o radier, e em seguida recebe os fechamentos e forros em drywall. Sua construção dura em média 45 dias. O estande é demolido quando não há mais espaço disponível pelo avanço das obras, sendo substituído pelo tipo 2, ou quando terminam as vendas, aí não sendo feito mais nenhum estande no terreno. A Figura 3 ilustra o tipo.

Figura 3 - Exemplo de estande tipo 1. Vila Felice, 2014, Hortolândia - SP

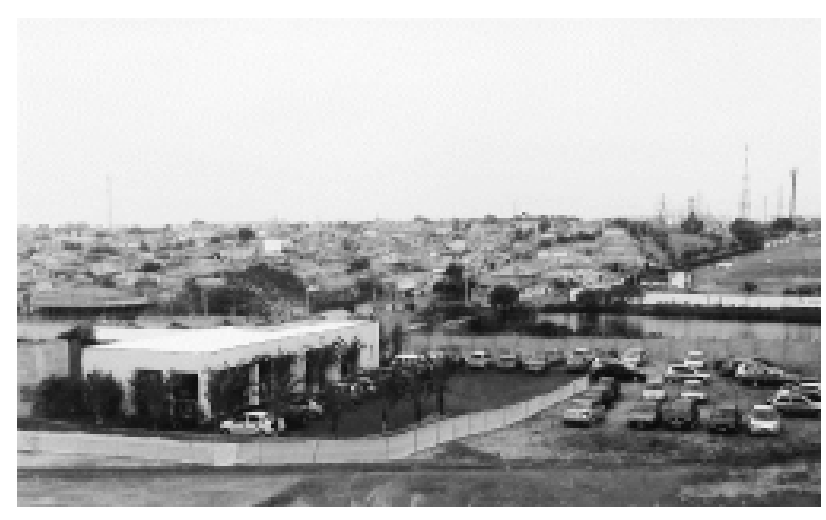

Fonte: Foto dos autores.

Além da construção com a montagem de todos os elementos no terreno, tem sido vistos estandes cuja estrutura principal parte de containers, permitindo sua reprodução em outro terreno.

\section{Tipo 2 - Localizado no terreno, sem prejuízo do andamento da obra}

São a versão reduzida do tipo anterior, sempre na forma de um pequeno retângulo ou quadrado; construído geralmente com material reaproveitado do estande original após sua demolição, podendo também ser em container (Figura 4). Como não é bom que o terreno fique sem nenhum local específico de atendimento enquanto as vendas ainda estão acontecendo, após a demolição do estande original de metragem maior e unidade decorada, são construídos em metragem reduzida (20 a 30 $\mathrm{m}^{2}$ ) e permanecem até a fase final da obra havendo espaço disponível. Tem a função proporcionar local adequado para um ou dois 
corretores, sendo isolado do canteiro de obras. Geralmente tem apenas um lavabo e se houver espaço, uma copa para apoio.

Em muitos casos, quando não há disponibilidade de espaço ou verba para um estande maior, o tipo 2 é utilizado para todo o lançamento. Também são usados containers para essa finalidade, quando não se deseja construir por que o estande será necessário por um período de poucos meses, sendo assim mais vantajoso o aluguel de um container.

Figura 4 - Tipo 2, estande de empreendimento residencial de alto padrão em São Paulo

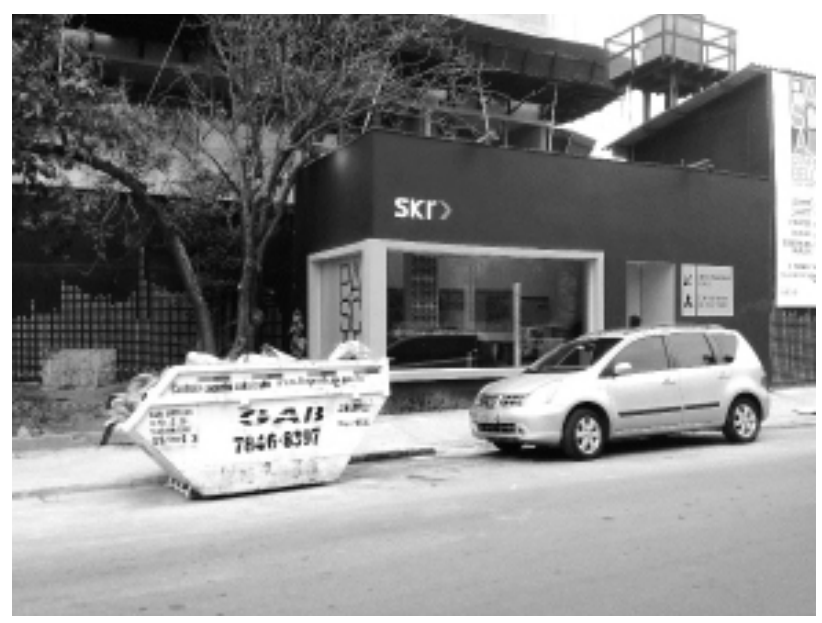

Fonte: Foto dos autores.

\section{Tipo 3 - Estandes em edificações de caráter permanente}

São estandes que se instalam para duração comum (média de 1 a 2 anos) em imóveis de caráter definitivo existentes no próprio terreno ou imediações. Quando instalados nas imediações, como avenidas locais, geralmente são locados imóveis comerciais para a adaptação. Esta implantação se relaciona com o fato de que ruas de baixo movimento e estritamente residenciais, mais afastadas das vias principais estejam recebendo lançamentos, forçando a busca por um ponto de maior visibilidade local.

Já no próprio terreno, o imóvel residencial ou comercial é utilizado. Estando em boas condições de conservação, representa uma alternativa econômica se comparado à construção de um edifício totalmente novo. No caso da adaptação de construção no próprio terreno, que ou pode manter-se intacta ou ser remanescente de demolição parcial, devem ser observadas as condições de implantação da obra, para que seu uso possa ser validado.

A Figura 5A ilustra o caso de uso de edificação remanescente no próprio terreno, para um lançamento comercial em área nobre na zona sul de São Paulo. Essa edificação estava implantada de forma conveniente no terreno, que não dispunha de muito espaço disponível, colada ao alinhamento e a um dos cantos, permitindo o avanço da obra. Não foi construída unidade decorada. A adaptação do estande neste espaço foi realizada em uma semana, prazo bastante conveniente para o início imediato das vendas.

A Figura 5B mostra uma edificação comercial em via local, no município de Hortolândia, interior de São Paulo, usada como estande para um lançamento residencial, onde no espaço interno foi construída uma unidade decorada. Após o uso por este empreendimento, a adaptação realizada foi aproveitada por outra incorporadora que se instalou no local para a venda de um lançamento também residencial.

Essa opção tem sido vista frequentemente em empreendimentos de todos os padrões.

\section{Tipo 4 - Quiosques em espaços cobertos}

Figura 5 - Exemplos de estandes em edificações permanentes
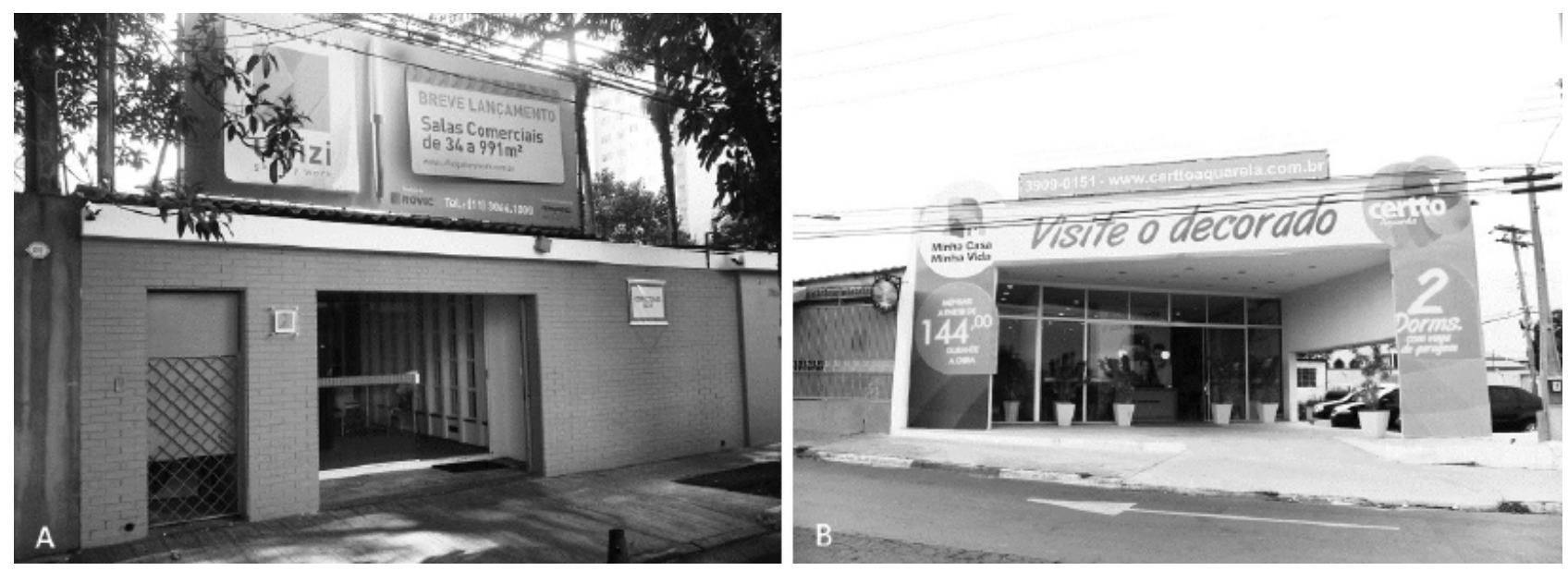

Fonte: Foto dos autores. 
Plantão de dimensões reduzidas que opera em shopping centers e outros locais cobertos de acesso público. Usado em ações promocionais de curta, média ou longa permanência. A configuração desses quiosques é regida pelo regulamento interno do shopping, que dentre uma série de diretrizes, tem como principal a que determina aspectos ligados a possível bloqueio da visão do corredor pelo mobiliário, que tem altura máxima determinada. 0 intuito do quiosque não é necessariamente servir como um estande de fato, mas sim, como um ponto de informações, onde podem ser vistos um ou os diversos empreendimentos de uma incorporadora. O quiosque é estratégico canal de atendimento pois marca presença em uma situação onde o consumidor já está inserido em um ambiente de compras e serviços, no caso dos shoppings, prestando atenção nas diversas informações que recebe visualmente de tudo o que há em volta. O shopping ou lugares de grande trânsito de pessoas, não é o primeiro local que vem em mente quando se pensa em procurar um empreendimento, no entanto, é cada vez mais frequente encontrar quiosques e até mesmo lojas de incorporadoras em shoppings de diversas segmentações de público por todo o país.

Além da promoção de empreendimentos diversos, os quiosques muitas vezes aparecem como um ponto de venda para as próprias instalações do shopping onde se encontram, como exemplo da Figura 6.

Figura 6 - Quiosque para venda de lojas do próprio shopping - SP

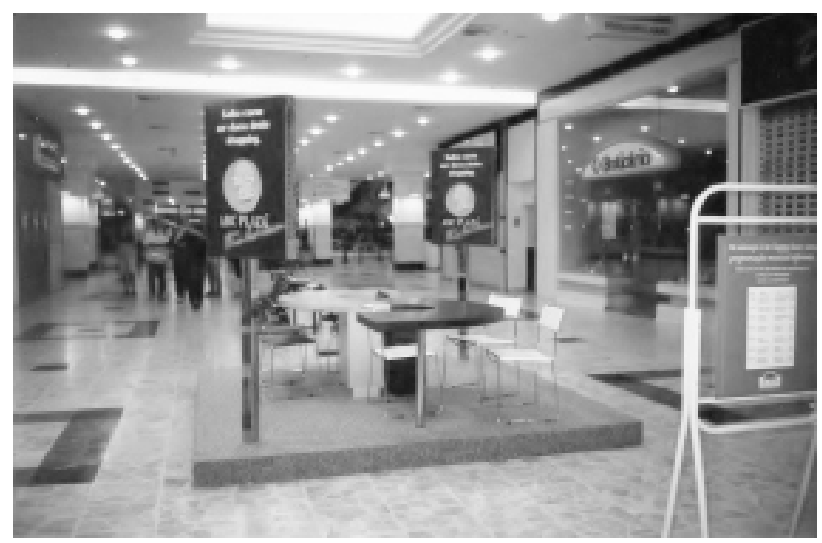

Fonte: Foto dos autores.

\section{Tipo 5 - Estandes móveis}

São os estandes sobre rodas. Atualmente é o tipo menos usado dentretodos esua óbvia caracterização não demanda maiores explicações. A possibilidade de usar caminhões permite que os estandes sejam itinerantes. Essa é uma tendência que tem caído no gosto do público brasileiro nos últimos anos, e que ainda está em seus testes iniciais no mercado imobiliário, que os tem utilizado em produtos de padrão médio e popular. Aos poucos percebe-se maior aceitação quanto a impermanência de pontos comerciais. São exemplos os trailers, food-trucks, pop-up stores e até mesmo escritórios diversos sobre rodas. Tal familiarização do público com esta modalidade pode fazer com que os estandes móveis possam ser vistos com maior frequência no futuro, principalmente se passarem por uma reformulação projetual, que os deixe visualmente mais agradáveis. As tiny houses (mini-casas) norte-americanas ou europeias, muitas vezes construídas sobre rodas, são um exemplo de que os estandes móveis podem ser arquitetonicamente interessantes, e não apenas funcionais, onde fica a cargo da comunicação visual sua decoração e personalização.

As instalações de atendimento podem ser adaptadas nos baús e carrocerias dos caminhões (Figura 7A) ou construídos a partir reboques e semirreboques, que podem até mesmo desprender-se do caminhão por alguns dias em determinado ponto (Figura 7B). Em ambas, preservou-se o aspecto do caminhão e da plataforma utilizada para atendimento.

Como vantagens, tem o lado positivo de poder transitar entre várias ruas ou bairros promovendo um empreendimento local ou sendo uma central de vendas com todos os empreendimentos da incorporadora, como no exemplo da Figura 7. O estande móvel é considerado como um tipo relacionado a uma iniciativa sustentável, porque evita a ocupação do terreno. Dependendo do bairro e das dimensões do empreendimento a preferência pode ser para o estande fixo, sendo o sobre rodas um apoio para sua promoção. Também se adapta bem a situações de empreendimentos em localidades de turismo, podendo acompanhar o vai e vem dos finais de semana.

Figura $7 a$ - Estande sobre rodas

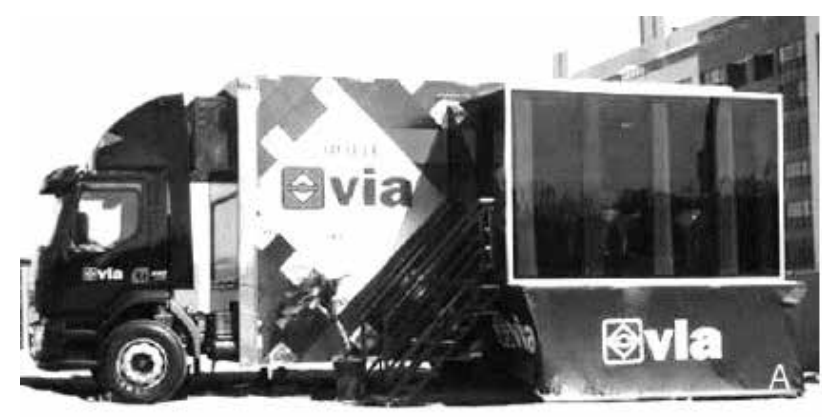

Fonte: Figura 7a Blog Edmar Junior 
Figura 7b Estande sobre rodas

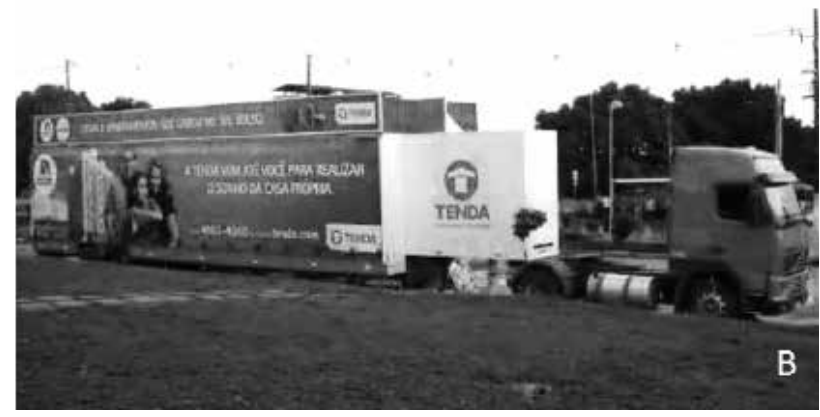

Fonte: Figura 7b Portal Marketing Imobiliário

\section{Tipo 6 - Estandes em feiras e exposições}

São estandes montados para curta duração em pavilhões, para participação do incorporador em eventos como feirões e exposições. São instalados de acordo com a malha determinada pelos promotores do evento (masterplan).

Esse tipo de estande por estar sob local coberto, segue o padrão construtivo utilizado por montadoras especializadas, como octanorm, treliças, compensados, plásticos e demais componentes visando fácil montagem e desmontagem, já que as feiras e exposições duram em média apenas alguns dias. Como não precisam atender ao rigor das intempéries e questões de segurança por estarem dentro de um pavilhão, podem ter sua forma concebida de maneira mais conceitual, explorando cores, texturas, formas e volumetrias, no entanto, também podem manter a configuração mais simples, seguindo a padronização dos elementos construtivos (Figura 8).

Fora os feirões de imóveis, onde o público vai com real intenção de direcionar ou fechar negócio, pois nessas ocasiões costumam ser concedidos bons descontos, os estandes em feiras têm objetivos mais comerciais com relação ao posicionamento de mercado das incorporadoras.

Figura 8 - Estandes de incorporadoras e imobiliárias no pavilhão Anhembi São Paulo. Feirão da Casa Própria

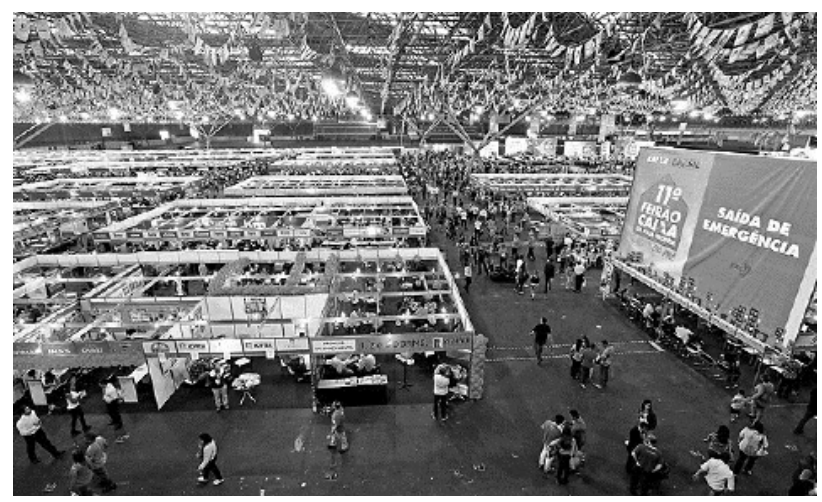

Fonte: <http://www1.folha.uol.com.br/ mercado/2016/04/1766069-caixa-inicia-feirao-da-casa-propriano-rj-nesta-sexta-feira.shtml> acesso em 27/06/2016

\section{Tipo 7 - Estandes em pátios descobertos}

São montados em espaços abertos, formados por pavilhões em estrutura e cobertura leve, de fácil desmontagem (Figura 9), geralmente composto pelos mesmos perfis e treliças metálicas usadas nos estandes para feiras, tipo anterior. Servem para ações promocionais em grandes estacionamentos ou locais abertos de natureza diversificada. Percebeu-se nos estandes encontrados que geralmente são usados para a promoção de empreendimentos populares, não se tratando de apenas um, mas de determinada parte da carteira da incorporadora. Juntamente com os quiosques em shoppings, este tipo é o que mais expressa a flexibilização do ponto de venda imobiliário em lugares não previsíveis para esta apresentação, explorando a visibilidade decorrente do alto tráfego de pessoas de determinados locais em torno do qual pode orbitar. Assim como o Tipo 6, o espaço para implantação e a estrutura são alugados, e os estandes precisam ser montados e desmontados rapidamente, de forma a não causar transtorno no local fora do período combinado, o que explica a simplicidade das instalações.

Figura 9 - Estande montado para um feirão da incorporadora MRV em Guarulhos

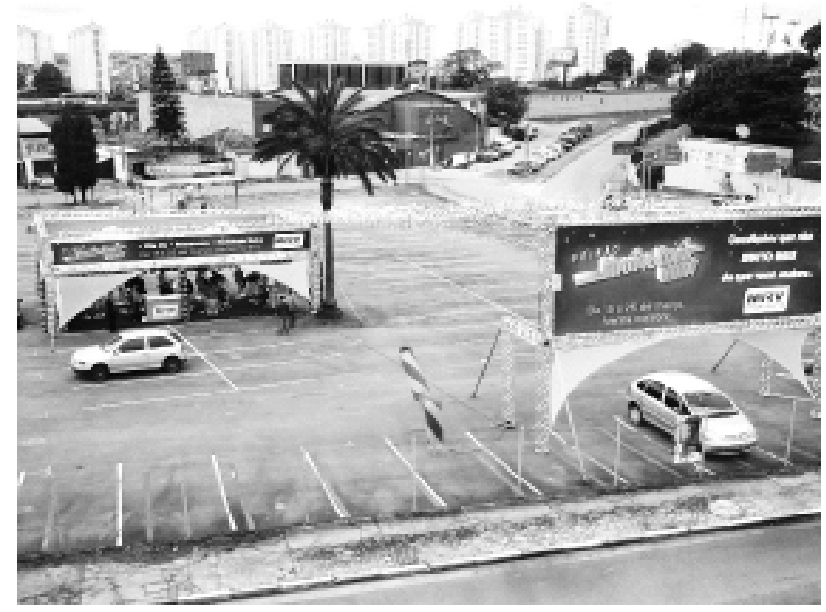

Fonte: TDVA Produção de Eventos

\section{CONCLUSÃO}

Geralmentedesapercebidosnaconstantetransformação da cidade, os estandes imobiliários representam uma temática ainda pouco explorada dentro da arquitetura contemporânea, carecendo da juntada de informações para estudo, classificação e descrição de sua história e manifestações, podendo ser situadas no tempo.

A arquitetura em todo esse trajeto se aperfeiçoa e, apesar de haver uma grande lacuna ocasionada pela falta de fotografias de época e registros da aparência 
dos estandes antes da década de noventa, visivelmente houveram transformações importantes nesse campo. $\mathrm{O}$ aspecto do estande no local, foi e tem sido bastante explorado como recurso de visual merchandising, no entanto, exploram-se agora também as tipologias possíveis, testando a aproximação com o público, em que a forma acompanha as possibilidades da propaganda e do local definido como ponto de venda.

Atualmente o consumidor não deseja ser incomodado e se sentirá desconfortável com uma abordagem indesejada de algum vendedor ou propaganda. Bastam segundos para que uma ação invasiva seja percebida e ignorada. Isso faz com que as companhias tenham que inventar constantemente novas formas de estar presente para esse consumidor, entendendo que dele parte a decisão de compra. Estar presente de forma consistente, receptiva e indireta é o grande desafio atual, não só no ramo imobiliário, mas no mercado em geral. No meio digital, na internet, essa abordagem já é praticada, e a variedade de pontos de venda possíveis é o reflexo deste comportamento no meio físico. Cada lançamento é diferente, acontece em um local que possui sua própria dinâmica, tem seu público alvo, e são esses fatores, aliados a verba disponível, que regem a escolha pelo tipo.

Ao pensar no estande de vendas, cabe aos profissionais de marketing, propaganda e arquitetura, levarem em conta o programa e se interrogarem a respeito da percepção e interação do público com essas instalações, questionando-se sempre sobre como um cada desses tipos pode funcionar melhor.

\section{REFERÊNCIAS}

ABUSSAMRA, Jorge Munif. O edifício residencial paulistano nos anos 70, 80 e 90: a arquitetura e o mercado imobiliário. Dissertação (Mestrado em Arquitetura e Urbanismo). Universidade São Judas Tadeu, São Paulo, 2007.

ALEXANDER, Christhofer. A pattern language. New York, Oxford University Press, 1977.

BASTOS, Carlos Alberto Albuquerque. A importância do "stand de vendas" para o marketing imobiliário. Monografia (Especialização). Universidade Candido Mendes, Rio de Janeiro, 2004.

DA SILVA, Luís Octávio. A constituição das bases para a verticalização na cidade de São Paulo. Arquitextos, São Paulo, ano 07, n. 080.05, Vitruvius, jan. 2007. Disponível em: <http://www.vitruvius.com.br/revistas/read/arquitextos/07.080/280>.

HERTZBERGER, Hermann. Lições de arquitetura. São Paulo, Martins Fontes: 1996.

KRAUEL, Jacobo. Arquitecture y Diseno Stands 6. Barcelona, Espanha: Links Books, 2008.

LEITE, Luiz Ricardo Pereira. Estudo das Estratégias das Empresas Incorporadoras do Município de São Paulo no Segmento Residencial no Período 1960-1980. Dissertação (Mestrado). Universidade de São Paulo. São Paulo, 2006.

MORAES, Sandra Regina Casagrande de. O arquiteto e o mercado imobiliário residencial na Cidade de São Paulo no Século XXI (2000-2011). 2013. Tese (Doutorado). Universidade Presbiteriana Mackenzie, São Paulo, 2013.

PINHEIRO, Maria Lúcia Bressan. Arquitetura residencial verticalizada em São Paulo nas décadas de 1930 e 1940. An. mus. paul., São Paulo,v. 16, n. 1, p. 109-149, June 2008. Disponível em <http://www.scielo.br/scielo.php? script=sci arttext\&pid=S0101-47142008000100004\&ln g=en\&nrm=iso>. Accesso em 12 Aug. 2016. http://dx.doi.org/10.1590/S0101-47142008000100004.

PSILLAKIS, H. M. Marketing Imobiliário - Variáveis de Decisão. RAE - Revista de Administração de Empresas, v. 15, n. 6, nov-dez, 1975.

SANTOS, Demósthenes Magno. A história da construtora Alfredo Mathias 1950 - 1985. São Paulo, 2013. Dissertação (Mestrado em Arquitetura e Urbanismo), FAAUSP, São Paulo, 2013.

\section{SITES:}

https://quandoacidade.wordpress.com/2014/12/17/a-cidade-era-mais-gentile/cia-city-rua-libero-badaro/ http://www.tdva.com.br/blog/category/estande/page/2/

http://www1.folha.uol.com.br/mercado/2016/04/1766069-caixa-inicia-feirao-da-casa-propria-no-rj-nesta-sexta-feira.shtml http://blogdoedmarjunior.com.br/2013/10/04/stand-movel-um-novo-conceito-lancado-pela-via/

http://www.architectural-review.com/archive/viewpoints/where-does-architecture-end-and-marketing-begin/8681435.fullarticle

http://www.marketingimob.com/2010/08/marketing-movel-no-mercado-imobiliario.html

http://www.copansp.com.br/

http://www3.prefeitura.sp.gov.br/cadlem/secretarias/negocios juridicos/cadlem/integra.asp?alt=16042014D\%20550360000\%20\%20 \%20\%20\%20\%20\%20\%20\%20\%20\%20\%20\&secr=\&depto=\&descr tipo=DECRETO

NOTA DO EDITOR (*) O conteúdo do artigo e as imagens nele publicadas são de responsabilidade do(s) autor(es). 